\title{
Population model for Amyloodinium ocellatum infecting the spotted seatrout Cynoscion nebulosus and the red snapper Lutjanus campechanus
}

\author{
Ignacio Masson, Jeffrey M. Lotz*, Reginald B. Blaylock
}

Gulf Coast Research Laboratory, The University of Southern Mississippi, Ocean Springs, Mississippi 39564, USA

\begin{abstract}
The dinoflagellate Amyloodinium ocellatum, a major pathogen in warm water mariculture, has a trophont, a tomont and a dinospore life history stage. This paper presents a population model for A. ocellatum infecting spotted seatrout Cynoscion nebulosus and red snapper Lutjanus campechanus and evaluates the relative effect of each vital rate on the A. ocellatum population growth rate. The vital rates were estimated by incubating trophonts in vitro and tracking their development through the successive life history stages at $25^{\circ} \mathrm{C}$ and $33 \mathrm{ppt}$. The A. ocellatum population growth rate was $1.90 \mathrm{~d}^{-1}$ for spotted seatrout and $1.92 \mathrm{~d}^{-1}$ for red snapper. Highest elasticity values ( 0.24 and 0.23 in spotted seatrout and red snapper, respectively) corresponded to transitions from the dinospore to the trophont stage, the trophont stage to the tomont stage and the tomont stage back to the dinospore stage in both host species (self-loops not included). A $50 \%$ change in vital rates showed that the mean number of dinospores produced by a tomont had the largest effect on the A. ocellatum population growth rate (15\%), followed by the dinospore infection rate $(14 \%)$, the tomont sporulation rate $(12 \%)$ and the dinospore mortality rate $(10 \%)$ in both host species. A comparison of modeled and experimental vital rate threshold values revealed a 2.5- (spotted seatrout) or a 2.6-fold (red snapper) difference in the values for dinospore mortality, which is the smallest difference among all the modeled and experimental vital rates. Therefore, measures that increase dinospore mortality have a greater likelihood of influencing the outcome of an epidemic.
\end{abstract}

KEY WORDS: Population model · Amyloodinium ocellatum • Epidemiology · Epidemic model · Amyloodiniosis $\cdot$ Fish disease $\cdot$ Spotted seatrout $\cdot$ Red snapper

\section{INTRODUCTION}

Amyloodiniosis, a parasitic disease caused by the dinoflagellate Amyloodinium ocellatum, represents one of the major impediments to the development of warm water mariculture (Paperna 1984a, Noga \& Levy 2006). The life cycle of A. ocellatum consists of a trophont stage parasitic on the gills and skin of fish, a free-living reproductive tomont stage and a freeswimming infectious dinospore stage (Brown 1934, Nigrelli 1936, Brown \& Hovasse 1946, Paperna 1984a). Trophonts are spherical to oval and attached to the gills and skin of fish (Brown 1934, Nigrelli 1936, Cheung et al. 1978, 1981). Trophonts increase in size and gradually detach from the fish. After detachment the trophont forms a solid body wall encapsulating the organism and transforms into the non-motile, freeliving tomont (Nigrelli 1936, Brown \& Hovasse 1946, Cheung et al. 1981). Tomonts divide and produce up to 256 flagellated, motile dinospores, although the number of dinospores produced per tomont is related to the size of the tomont and environmental factors such as temperature and salinity (Brown 1931, 1934, Nigrelli 1936, Brown \& Hovasse 1946, Paperna 
1984a). After tomont sporulation (hatching), the infective dinospores attach to a fish and transform into trophonts, thus completing the life cycle (Noga 1987). Clinical signs of amyloodiniosis include anorexia, dyspnoea and pruritis. Symptoms, however, typically do not occur until heavy infections are established and mortality is imminent. As a result, treatments often are of limited value.

The parasite is capable of surviving and reproducing in a wide variety of environmental conditions. Paperna (1984a) demonstrated that at $25^{\circ} \mathrm{C}$ all tomonts divided and produced motile dinospores, taking 2 to $3 \mathrm{~d}$ to sporulate at salinities of 20, 30, 40 and 50 ppt. He considered 23 to $27^{\circ} \mathrm{C}$ to be the optimum temperature for Amyloodinium ocellatum development based on tomont survival and fecundity. Masson et al. (2011) showed that $A$. ocellatum reproductive success is linked to both the size of the trophont and the number of dinospores, which, in turn, are linked to the time the trophont spends on the host and the number of trophonts the host can tolerate. Trophonts remained attached longer and attained a larger size in red snapper Lutjanus campechanus than in spotted seatrout Cynoscion nebulosus, and the trophont lethal load was significantly higher in spotted seatrout than in red snapper.

Despite the general descriptions of the course of an infection and some basic understanding of the factors that influence the success of the parasite's life cycle, other than Masson et al. (2011), no quantitative estimates of the survival and reproductive rates of the life history stages have been reported. If the survival and fecundity rates of the life history stages are known, the changes in numbers of the life history stages over time and the overall population growth rate can be captured in mathematical expressions and modeled in much the same manner as has been accomplished for other aquatic pathogens such as white spot syndrome virus (Lotz \& Soto 2002), Taura syndrome virus (Lotz et al. 2003) and necrotizing hepatopancreatitis (Vincent et al. 2004) to provide insight into which parameters might serve as a focus for the development of management and control strategies.

In this study, we developed a schematic representation of the events in the life cycle of Amyloodinium ocellatum and used a laboratory challenge model to estimate the vital rates for each process in 2 species of hosts, the spotted seatrout Cynoscion nebulosus and the red snapper Lutjanus campechanus. These estimates were then used to model the population dynamics of the parasite and to predict its population growth under specified conditions in the 2 model fish hosts. Finally, sensitivity and elasticity analyses were performed to evaluate the effects of the absolute and proportional changes in those vital rates (Benton \& Grant 1999, Ebert 1999) that might elucidate critical control points in the life cycle at which curative treatments could be directed.

\section{MATERIALS AND METHODS}

\section{Maintenance and propagation of Amyloodinium ocellatum in the laboratory}

A culture of Amyloodinium ocellatum was established by introducing a naturally infected wild striped mullet Mugil cephalus to a tank containing juvenile laboratory-reared spotted seatrout Cynoscion nebulosus, wild-caught striped mullet, Atlantic croaker Micropogonias undulatus, and spot Leiostomus xanthurus. The infection was maintained in a $570 \mathrm{l}$ tank filled with approximately $200 \mathrm{l}$ of seawater. The seawater was prepared with dechlorinated and aged tap water and Crystal Sea ${ }^{\circledR}$ Marinemix salt (Marine Enterprises International Inc.). Continuous aeration was supplied by air stones connected to a regenerative blower.

As fish died, they were removed from the tank, dissected and inspected to confirm infection with Amyloodinium ocellatum. Infected gills were excised and returned to the tank. Uninfected fish of the species previously mentioned, but most commonly Atlantic croaker and laboratory-reared spotted seatrout, were continuously added to the A. ocellatum source tank to sustain the infection. Salinity in the tank was maintained at $33 \pm 2$ ppt. Dechlorinated tap water was added periodically to account for evaporation. No mechanical filtration was used. Biofiltration was accomplished using submerged blue, bonded filter pads (Aquatic Ecosystems). Temperature was maintained at $25 \pm 2^{\circ} \mathrm{C}$ by controlling the air temperature with a thermostatically controlled heating and cooling unit. Temperature, salinity, alkalinity, pH and ammonia and nitrite concentrations were monitored daily to ensure parameters were within the desired ranges $\left(23\right.$ to $27^{\circ} \mathrm{C}, 31$ to $35 \mathrm{ppt}, 180$ to $240 \mathrm{ppm}$ $\mathrm{CaCO}_{3}, \mathrm{pH} 7.5$ to 8.5 and 0 to $0.25 \mathrm{ppm}$ and 0 to $1 \mathrm{ppm}$, respectively). Illumination in the room was provided by sets of standard fluorescent tubes with a $14 \mathrm{~h}$ light: $10 \mathrm{~h}$ dark photoperiod. Infected and uninfected fish were fed twice daily to satiation with commercial flakes (Aquatic Ecosystems) or pellets (Skretting). 


\section{Experimental protocol}

Trophonts used for the experiments were obtained by adding naïve, laboratory-reared spotted seatrout to the tank where the infection was maintained. Spotted seatrout showing behavioral signs of heavy infection were euthanized, dissected and processed to collect the trophonts. Gills were excised and placed in Petri dishes with seawater at $25^{\circ} \mathrm{C}$ and 33 ppt. After a few minutes, the detached trophonts were transferred individually to a 96-well culture plate (Corning Life Sciences) (i.e. 1 trophont per well) using a glass pipette with a capillary tip. Wells were previously filled to half their volume $(0.16 \mathrm{ml})$ with seawater $\left(25^{\circ} \mathrm{C}, 33 \mathrm{ppt}\right)$. The length of each trophont was measured. The culture plate was incubated in the dark at $25^{\circ} \mathrm{C}\left(\mathrm{VWR}{ }^{\circledR} 1535\right.$ General Purpose Incubator). Culture plates were examined once daily in the morning to assess the survival of the trophonts, tomonts and dinospores, the number of tomont divisions, the time to sporulation and the number of dinospores produced by tomonts. Three trials were done such that 288 trophonts were monitored for development through the successive stages. Three trophonts were discarded due to error; therefore, the sample for this study consisted of a maximum of 285 trophonts. The time unit used in all cases is day.

\section{Development and diagrammatic representation of the population model}

Because Amyloodinium ocellatum has a life cycle with definite, discrete stages (like Ichthyophthirius multifiliis, for example, which has a trophont/trophozoite, a tomont/cyst and a tomite/theront stage; McCallum 1982, 1985, Noga 2000) and because the vital rates are dependent on the stage at which the organism is rather than on its age or size, we used a stage-structured type of population model to study its population dynamics. A graphical representation of the model is shown in Fig. 1. Each node represents 1 of the 3 life history stages of $A$. ocellatum. The arcs and arrows indicate the transitions between stages, which are regulated by the vital rate probabilities of each stage. These are as follows: $\mu_{\mathrm{Tr}}$, the probability that a trophont dies per day (the mortality rate of trophonts); $\mu_{\mathrm{To}}$, the probability that a tomont dies per day (the mortality rate of tomonts); $\gamma$, the probability that a tomont sporulates per day (the sporulation rate of tomonts); $N$, the mean number of dinospores produced by tomonts of the mean length; $\mu_{\mathrm{D}}$, the proba-

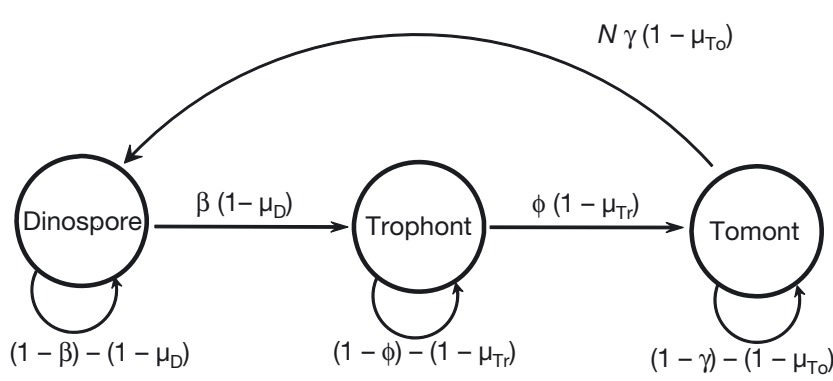

Fig. 1. Amyloodinium ocellatum. Life cycle graph for a pathogen population showing the transitions between and within stages and the associated vital rate probabilities; all arcs take one time period to complete. $\beta$ : probability that a dinospore infects a fish per day; $\mu_{D}$ : probability that a dinospore dies per day; $\phi$ : probability that a trophont detaches from a fish per day; $\mu_{\mathrm{Tr}}$ : probability that a trophont dies per day; $\gamma$ : probability that a tomont sporulates per day; $\mu_{\mathrm{To}}$ : probability that a tomont dies per day; $N$ : mean number of dinospores produced per tomont

bility that a dinospore dies per day (the mortality rate of dinospores); $\beta$, the probability that a dinospore infects a fish per day (the infection rate) $\phi \phi$, the probability that a trophont detaches from a fish per day (the detachment rate of trophonts).

\section{Estimation of the vital rate parameters}

Probability that a trophont dies per day $\left(\mu_{\mathrm{Tr}}\right)$. To estimate $\mu_{\mathrm{Tr}}$, we calculated the ratio of the number of trophonts that did not divide to the total number of incubated trophonts and multiplied the resulting value by the probability that a trophont detaches from spotted seatrout per day $(\phi)$, estimated in a previous study (Masson et al. 2011).

Probability that a tomont dies per day $\left(\mu_{\mathrm{To}}\right)$. To estimate $\mu_{\mathrm{To}}$, we counted the trophonts that transformed into tomonts and began dividing. For the tomonts that did not sporulate, the time at which they stopped dividing was recorded. These data were used to plot the number of tomonts that remained alive over time. Data were fit to the exponential function $y=a \mathrm{e}^{b x}$, with $1-\mathrm{e}^{b}$ being $\mu_{\mathrm{T}}$. Systat Version 12.0 (Systat 2007) was used to perform the curve fitting.

Probability that a tomont sporulates per day $(\gamma)$. $\gamma$ was obtained by plotting the cumulative percentage of unsporulated tomonts over time. The data were fit to the exponential function $y=a \mathrm{e}^{b x}$, with $1-$ $\mathrm{e}^{b}$ being $\gamma$. Systat Version 12.0 (Systat 2007) was used to perform the curve fitting.

Mean number of dinospores produced by tomonts of the mean length $(\boldsymbol{N})$. This parameter was estimated by maintaining tomonts in the 96-well culture 
plates and examining them once daily until sporulation. The number of tomites just before sporulation was used to determine the number of dinospores produced per tomont (i.e. each tomite produces 2 dinospores). We examined the relationship between the number of dinospores produced and tomont size. Linear regression was used to obtain a functional relationship between tomont length and the number of dinospores produced. Using this regression line, we calculated the number of dinospores produced by tomonts of the mean length.

Probability that a dinospore dies per day $\left(\mu_{D}\right) \cdot \mu_{D}$ was estimated by observing newly sporulated dinospores until dinospore motility ceased. Only data from tomonts releasing all dinospores within a $24 \mathrm{~h}$ period (i.e. between 2 consecutive observations) were used to construct the dinospore survival curve from which the probability of dinospore death per day was calculated. This ensured that all dinospores in each well had a maximum age difference of $24 \mathrm{~h}$.

Dinospore survival over time was fit to the exponential function $y=a \mathrm{e}^{b x}$, with $1-\mathrm{e}^{b}$ being $\mu_{\mathrm{D}}$. Systat Version 12.0 (Systat 2007) was used to perform the curve fitting.

Probability that a dinospore infects a host per day ( $\beta$ ). This probability was previously estimated in a separate study by individually exposing 25 spotted seatrout juveniles $(13.50 \pm 0.23 \mathrm{~cm}$ total length [TL], $22.83 \pm 1.22 \mathrm{~g})$ and 25 red snapper juveniles (5.84 \pm $0.15 \mathrm{~cm} \mathrm{TL}, 3.31 \pm 0.28 \mathrm{~g})$ to different dinospore doses (each in 2.51 of seawater) and quantifying the proportion of dinospores that attached to the fish and developed into trophonts after a $24 \mathrm{~h}$ exposure (Masson et al. 2011).

Probability that a trophont detaches from a fish per day $(\phi)$. Trophont detachment also was estimated in the above-mentioned study by individually infecting 26 spotted seatrout $(53.3 \pm 1.5 \mathrm{~mm}$ TL, $0.91 \pm$ $0.39 \mathrm{~g})$ and $11 \mathrm{red}$ snapper $(46.0 \pm 2.5 \mathrm{~mm}$ TL, $1.26 \pm$ $0.20 \mathrm{~g}$ ) with a known number of dinospores and accounting for the number of trophonts detached daily for $6 \mathrm{~d}$, the maximum time that trophonts remain attached to the host (Masson et al. 2011).

\section{Mathematical analysis of the population model}

The diagrammatic representation of Amyloodinium ocellatum population dynamics (Fig. 1) can be transformed into its equivalent matrix form $(\boldsymbol{M})$ to facilitate its analysis. In the life cycle graph, transitions are from the trophont stage to the tomont stage, from the tomont stage to the dinospore stage, and from the dinospore stage back to the trophont stage. Also, there are transitions represented by self loops (the probabilities of remaining in that stage). In a matrix, transitions always are from the class represented by a column to the class represented by a row, so the life cycle graph (Fig. 1) was translated from a node to a node into a column to a row in the matrix. In the transition matrix, $\boldsymbol{M}$, each row and each column represent a life cycle stage, where Row 1 and Column 1 represent the dinospore; Row 2 and Column 2, the trophont; and Row 3 and Column 3, the tomont. The matrix entries represent the probability of transitioning from one stage to another, e.g. entry in Row 2 and Column $1(2,1)$ is the probability of transformation of a dinospore (1) to a trophont (2).

$\boldsymbol{M}=\left[\begin{array}{ccc}(1-\beta)\left(1-\mu_{\mathrm{D}}\right) & 0 & N \gamma\left(1-\mu_{\mathrm{To}}\right) \\ \beta\left(1-\mu_{\mathrm{D}}\right) & (1-\phi)\left(1-\mu_{\mathrm{Tr}}\right) & 0 \\ 0 & \phi\left(1-\mu_{\mathrm{Tr}}\right) & (1-\gamma)\left(1-\mu_{\mathrm{To}}\right)\end{array}\right]$

The transition matrix $\boldsymbol{M}$, along with the estimates of the vital rates, was used to calculate the population growth rate (maximum eigenvalue), the sensitivities (change in the population growth rate with change in a parameter) and elasticities (percent change in growth rate per percent change in a parameter) for each of the parameters involved in the Amyloodinium ocellatum population model.

The Amyloodinium ocellatum asymptotic rate of population growth or simply the population growth rate $(\lambda)$ is given by the dominant eigenvalue of the transition matrix $\boldsymbol{M}$. The stable stage-structure distribution function (i.e. the function describing the proportions of each stage when the population is growing exponentially at a constant rate, $\lambda$ ) and the reproductive value function (i.e. the relative contribution to future population growth an individual in a certain stage is expected to make) are given by the corresponding right and left eigenvectors, $w$ and $v$. The sensitivity, $s_{i j}$, of $\lambda$ to changes in the matrix element, $a_{i j}$, of $\boldsymbol{M}$ is given by the partial differential $\delta$ (Benton \& Grant 1999). The symbol ' $<>$ ' in the equation below represents the scalar product of the vectors.

$$
s_{i j}=\frac{\delta \lambda}{\delta a_{i j}}=\frac{V_{i} w_{j}}{<w, V\rangle}
$$

Although the sensitivities measure how $\lambda$ changes with an absolute change in each $a_{i j}$, they can be scaled to test the effect of proportional changes of each $a_{i j}$ on $\lambda$. These new variables known as elastici- 
ties $\left(e_{i j}\right)$ represent the proportional contributions of each element in the transition matrix to $\lambda$ (Benton $\&$ Grant 1999).

$$
e_{i j}=\frac{a_{i j}}{\lambda} \frac{\delta \lambda}{\delta a_{i j}}=\frac{\delta \log \lambda}{\delta \log a_{i j}}
$$

The effect of a $50 \%$ change in each vital rate on $\lambda$ was determined in spotted seatrout and red snapper, and the vital rate threshold values (point where $\lambda=1$ ) for the Amyloodinium ocellatum population increase were estimated by performing iterations of the vital rate values for the transition matrix $\boldsymbol{M}$. Mathcad 13 (Mathsoft 2005) was used for the calculations.

\section{RESULTS}

\section{Estimation of the vital rate parameters}

Probability that a trophont dies per day $\left(\mu_{\mathrm{Tr}}\right)$. Only 2 out of the 285 (0.007) incubated trophonts of Amyloodinium ocellatum failed to divide and sporulate. $\mu_{\mathrm{Tr}}$ was then calculated multiplying the ratio of dead trophonts to the total number of incubated trophonts by the trophont detachment rate in spotted seatrout Cynoscion nebulosus and red snapper Lutjanus campechanus ( $\phi_{\mathrm{st}}$ and $\phi_{\mathrm{rs}}$, respectively) with $\phi_{\mathrm{st}}=$ 0.39 trophonts $\mathrm{d}^{-1}(0.37$ to $0.41,95 \% \mathrm{CI})$ and $\phi_{\mathrm{rs}}=$ 0.34 trophonts $\mathrm{d}^{-1}(0.32$ to $0.36,95 \% \mathrm{CI}$ ) (Masson et al. 2011). The resulting value for $\mu_{\mathrm{Tr}}$ in spotted seatrout $\left(\mu_{\operatorname{Tr} s t}\right)$ was 0.0027 trophonts $\mathrm{d}^{-1}(0.0026$ to $0.0029,95 \% \mathrm{CI})$ and in red snapper $\left(\mu_{\mathrm{Tr} r \mathrm{rs}}\right)$ it was 0.0024 trophonts $\mathrm{d}^{-1}(0.0022$ to 0.0025$)$.

Probability that a tomont dies per day $\left(\mu_{\mathrm{To}}\right)$. Fig. 2 shows the number of live tomonts over time and the best fit exponential curve $y=a \mathrm{e}^{b x}$ used to estimate $\mu_{\text {To, }}$ with $\mu_{\text {To }}=1-\mathrm{e}^{b}$. The estimated value for $\mu_{\text {To }}$ was 0.010 tomonts $\mathrm{d}^{-1}(0.004$ to $0.016,95 \% \mathrm{CI})$.

Probability that a tomont sporulates per day $(\gamma)$. The mean $\gamma$ was calculated from the best fit exponential curve for the expression $y=a \mathrm{e}^{b x}$, where $\gamma=1-\mathrm{e}^{b}$ (Fig. 3). These data were obtained by observing 268 tomonts (of the 285 originally incubated trophonts, 2 died and 15 did not sporulate, leaving a total of 268 tomonts for this part of the study) of various sizes ranging from 32 to $112 \mu \mathrm{m}$ for sporulation over time (Fig. 4). The estimated value for $\gamma$ was 0.35 tomonts $\mathrm{d}^{-1}(0.25$ to $0.45,95 \% \mathrm{CI})$.

Mean number of dinospores produced by tomonts of the mean length $(\boldsymbol{N})$. Fig. 5 shows the number of dinospores produced by each one of 268 tomonts of different lengths and the best fit regression line. Masson et al. (2011) estimated the mean

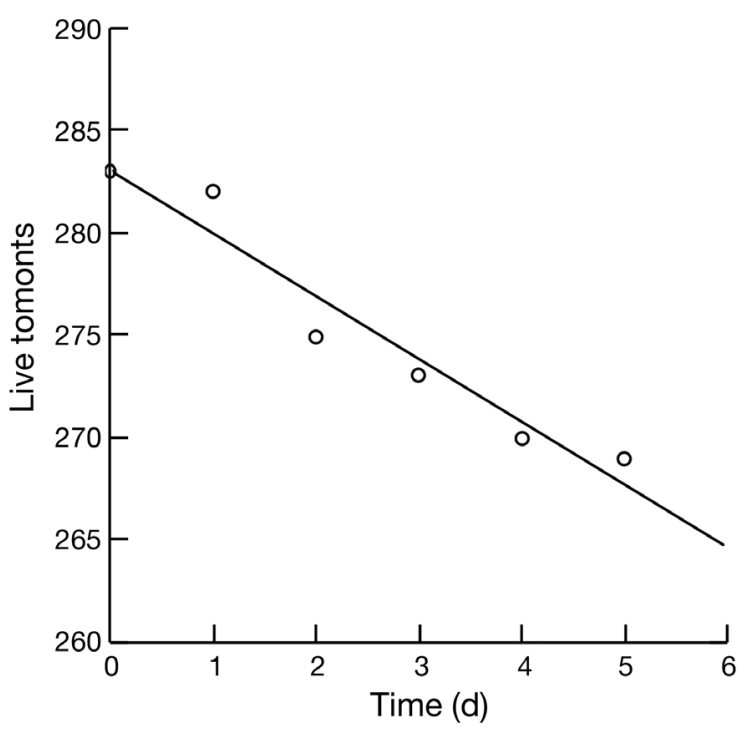

Fig. 2. Amyloodinium ocellatum. Number of tomonts remaining alive over time. Observed data (circles) and best fit exponential curve used to estimate the death rate of the tomonts $\left(\mu_{\mathrm{To}}\right)$

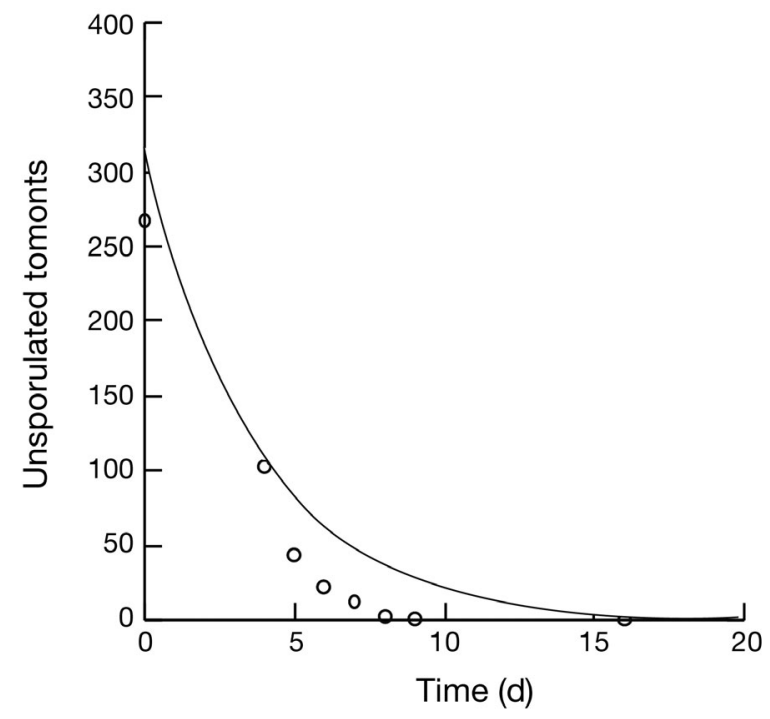

Fig. 3. Amyloodinium ocellatum. Number of unsporulated tomonts over time. Observed data (circles) and best fit exponential curve used to estimate the sporulation rate of the tomonts $(\gamma)$

length of tomonts from spotted seatrout to be $71.55 \mu \mathrm{m}$ (68.89 to $74.21,95 \% \mathrm{CI}$ ) and $79.83 \mu \mathrm{m}$ (77.09 to $82.57,95 \%$ CI) for red snapper, with significant differences between mean values $(\mathrm{p}<$ 0.05). From the regression equation, we estimated that tomonts of mean length produced 81.90 dinospores tomont $^{-1}$ (66.10 to 97.31 , $95 \%$ CI) for spotted seatrout and 98.90 dinospores tomont ${ }^{-1}$ (82.16 to $115.65,95 \%$ CI) for red snapper. 


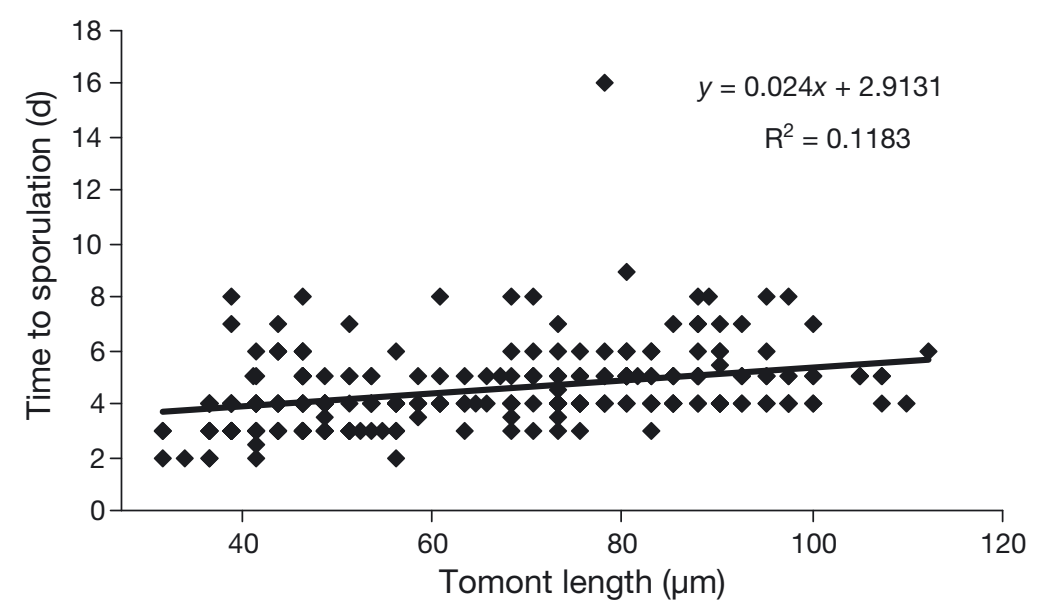

Fig. 4. Amyloodinium ocellatum. Time to sporulation of 268 tomonts of different lengths and regression line to estimate the mean time to sporulation for tomonts of mean length

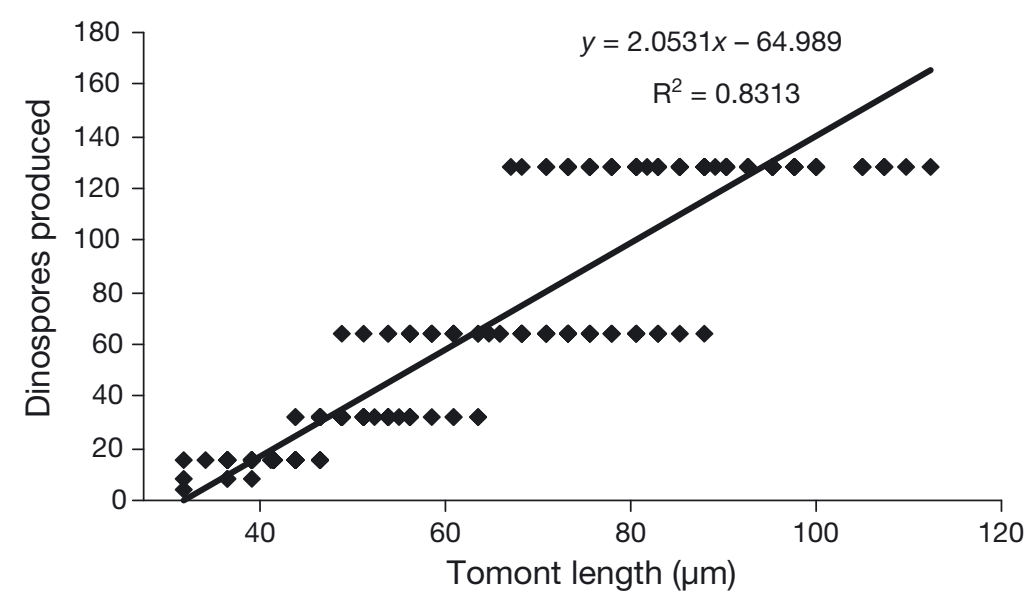

Fig. 5. Amyloodinium ocellatum. Number of dinospores produced by 268 tomonts of different lengths and the regression line used to estimate the mean number of dinospores produced by tomonts of the mean length

\section{Mathematical analysis of the population model}

The vital rate estimates for Amyloodinium ocellatum infections in spotted seatrout and red snapper were entered in the transition matrix $(\boldsymbol{M})$. The resulting transition matrices for the life cycle of A. ocellatum infecting spotted seatrout $\left(\boldsymbol{M}_{\mathrm{st}}\right)$ and red snapper $\left(\boldsymbol{M}_{\mathrm{rs}}\right)$ were:

$$
\begin{aligned}
& \boldsymbol{M}_{\text {st }}=\left[\begin{array}{ccc}
0.3968 & 0 & 28.3783 \\
0.2232 & 0.6077 & 0 \\
0 & 0.3886 & 0.6435
\end{array}\right] \\
& \boldsymbol{M}_{\mathrm{rs}}=\left[\begin{array}{ccc}
0.4092 & 0 & 34.2689 \\
0.2108 & 0.6578 & 0 \\
0 & 0.3388 & 0.6435
\end{array}\right]
\end{aligned}
$$

The Amyloodinium ocellatum population growth for spotted seatrout $\left(\lambda_{\mathrm{st}}\right)$ was $1.90 \mathrm{~d}^{-1}$, whereas for red snapper $\left(\lambda_{\mathrm{rs}}\right)$ it was $1.92 \mathrm{~d}^{-1}$. The stable stage-structure functions for the A. ocellatum life cycle in spotted seatrout $\left(W_{\mathrm{st}}\right)$ and red snapper $\left(W_{\mathrm{rs}}\right)$ are shown below, with the top to bottom values in the matrices representing the proportional contributions of the dinospore, trophont and tomont stages, respectively.

$$
\begin{gathered}
W_{\mathrm{st}}=\left[\begin{array}{l}
1.0000 \\
0.1722 \\
0.0531
\end{array}\right] \\
W_{\mathrm{rs}}=\left[\begin{array}{l}
1.0000 \\
0.1667 \\
0.0442
\end{array}\right]
\end{gathered}
$$

Likewise, the reproductive value functions for the Amyloodinium ocellatum life cycle in spotted seatrout $\left(V_{\mathrm{st}}\right)$ and red snapper $\left(V_{\mathrm{rs}}\right)$ are as follows:

$$
\begin{gathered}
V_{\mathrm{st}}=\left[\begin{array}{c}
1.0000 \\
6.7514 \\
22.5185
\end{array}\right] \\
V_{\mathrm{rs}}=\left[\begin{array}{c}
1.0000 \\
7.1787 \\
24.7941
\end{array}\right]
\end{gathered}
$$
$\mathrm{p}=0.00)$. 


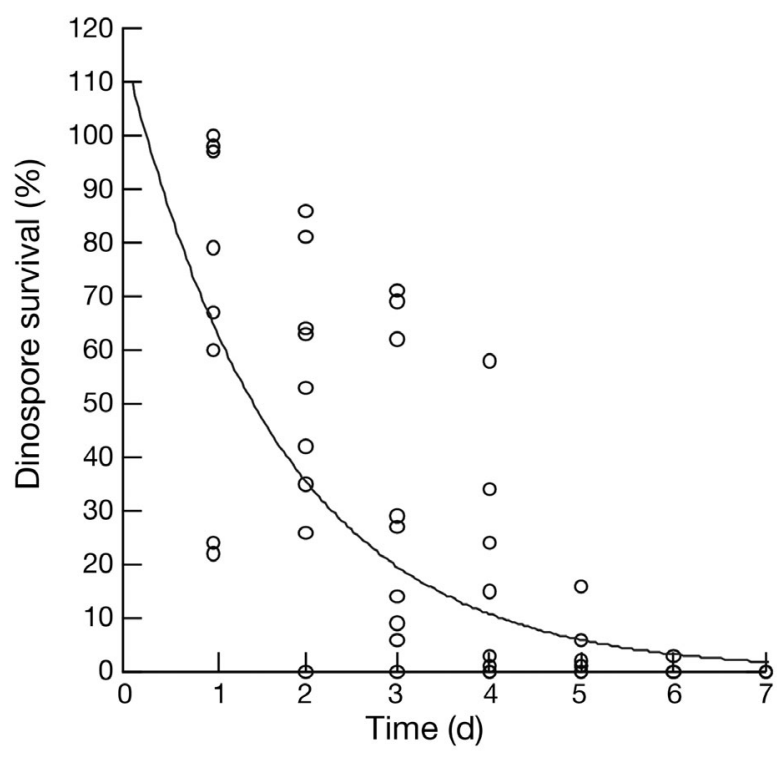

Fig. 6. Amyloodinium ocellatum. Survival of dinospores produced by 20 tomonts individually incubated. Observed data (circles) and best fit exponential curve used to estimate the death rate of the dinospores $\left(\mu_{\mathrm{D}}\right)$

The following are the sensitivities for the Amyloodinium ocellatum life cycle in spotted seatrout $\left(S_{\mathrm{st}}\right)$ and red snapper $\left(S_{\mathrm{rs}}\right)$ :

$$
\begin{aligned}
S_{\mathrm{sr}} & =\left[\begin{array}{ccc}
0.2977 & 0 & 0.0158 \\
2.0102 & 0.3462 & 0 \\
0 & 1.1547 & 0.3650
\end{array}\right] \\
S_{\mathrm{rs}} & =\left[\begin{array}{ccc}
0.2959 & 0 & 0.0131 \\
2.1240 & 0.3540 & 0 \\
0 & 1.3214 & 0.3501
\end{array}\right]
\end{aligned}
$$

The resulting elasticities for the Amyloodinium ocellatum life cycle in spotted seatrout $\left(E_{\mathrm{st}}\right)$ and red snapper $\left(E_{\mathrm{rs}}\right)$ were:

$$
\begin{aligned}
& E_{\mathrm{st}}=\left[\begin{array}{ccc}
0.0621 & 0 & 0.2357 \\
0.2357 & 0.1105 & 0 \\
0 & 0.2357 & 0.1203
\end{array}\right] \\
& E_{\mathrm{rs}}=\left[\begin{array}{ccc}
0.0630 & 0 & 0.2329 \\
0.2329 & 0.1211 & 0 \\
0 & 0.2329 & 0.1172
\end{array}\right]
\end{aligned}
$$

The maximum elasticity values corresponded to the transitions from the dinospore to the trophont stage, from the trophont stage to the tomont stage and from the tomont stage back to the dinospore stage in both host species. The values were 0.2357 and 0.2329 in spotted seatrout and red snapper, respectively. This means that a $1 \%$ change in each matrix component $\left[\beta\left(1-\mu_{\mathrm{D}}\right), \phi\left(1-\mu_{\mathrm{Tr}}\right)\right.$, or $\left.N \gamma\left(1-\mu_{\mathrm{To}}\right)\right]$ will increase $\lambda$ by 0.2357 and $0.2329 \%$, in spotted seatrout and red snapper, respectively. The elasticity values for these 3 transitions in their respective host are the same because they are within the same loop (i.e. a circuit of arcs returning to the starting compartment and encountering no compartment more than once), and by definition they must have the same values (Benton \& Grant 1999).

Because each matrix component involved $>1$ vital rate, we analyzed the effect of a $50 \%$ change in each vital rate on the Amyloodinium ocellatum population growth rate in spotted seatrout $\left(\lambda_{\mathrm{st}}\right)$ and red snapper $\left(\lambda_{\mathrm{rs}}\right)$ (Table 1). In both species, the greater percent increase in $\lambda$ for a $50 \%$ change in a vital rate was given by $N, \beta$, $\gamma$ and $\mu_{\mathrm{D}}$ (in decreasing order). In addition, equal changes in $\mu_{\text {To }}$ and $\mu_{\text {Tr }}$ had little effect $(<0.2 \%)$ on $\lambda$.

Further analysis of the vital rates showing the threshold values for Amyloodinium ocellatum population increase $(\lambda=1)$ in spotted seatrout and red snapper is presented in Table 2 . When comparing these values with the vital rates estimated from the experiments (Table 3), we noticed that a 2.5- and 2.6-fold increase in $\mu_{\mathrm{D}}$ (for spotted seatrout and red snapper, respectively) brings this vital rate value below the threshold limit for an epidemic to occur. Instead, $N$ would need to be reduced 29.1 and 34.3 times (for spotted seatrout and red snapper, respectively) to end up below its threshold value; $\beta$ would need to be decreased 45.5 and 53.3 times its actual value and $\gamma$ would need to be reduced 1178.0 and 1767.0 times its actual value to prevent an epidemic (for spotted seatrout and red snapper, respectively). Regarding the mortality rate of the tomont $\left(\mu_{\mathrm{To}}\right)$, its magnitude would need to be increased 91.1

Table 1. Amyloodinium ocellatum. Effect of a $50 \%$ change in a vital rate on the increase in A. ocellatum population

\begin{tabular}{|c|c|c|}
\hline \multirow{2}{*}{$\begin{array}{l}\text { Vital } \\
\text { rate }\end{array}$} & \multicolumn{2}{|c|}{ - Increase population growth rate (\%) - } \\
\hline & Spotted seatrout & Red snapper \\
\hline$N$ & 15.34 & 15.30 \\
\hline$\beta$ & 13.61 & 13.68 \\
\hline$\gamma$ & 11.91 & 12.00 \\
\hline$\mu_{\mathrm{D}}$ & 10.32 & 10.28 \\
\hline$\mu_{\mathrm{To}}$ & 0.19 & 0.18 \\
\hline$\mu_{\operatorname{Tr}}$ & 0.06 & 0.05 \\
\hline$\phi$ & Not computed due $t$ & rence with $N$ \\
\hline
\end{tabular}
growth rate for infections in spotted seatrout Cynoscion nebulosus and red snapper Lutjanus campechanus. Refer to Fig. 1 for the definition of symbols 
Table 2. Amyloodinium ocellatum. Vital rate threshold values for A. ocellatum population increase $(\lambda=1)$ and fold difference with their actual values for infections in spotted seatrout Cynoscion nebulosus and red snapper Lutjanus campechanus. Refer to Fig. 1 for the definition of symbols

\begin{tabular}{|c|c|c|c|c|c|c|}
\hline \multirow{2}{*}{$\begin{array}{l}\text { Vital } \\
\text { rate }\end{array}$} & \multicolumn{3}{|c|}{$\longrightarrow$ Spotted seatrout } & \multicolumn{3}{|c|}{ Red snapper } \\
\hline & $\begin{array}{c}\text { Threshold } \\
\text { value }\end{array}$ & $\begin{array}{l}\text { Actual } \\
\text { value }\end{array}$ & $\begin{array}{c}\text { Fold } \\
\text { difference }\end{array}$ & $\begin{array}{c}\text { Threshold } \\
\text { value }\end{array}$ & $\begin{array}{l}\text { Actual } \\
\text { value }\end{array}$ & $\begin{array}{c}\text { Fold } \\
\text { difference }\end{array}$ \\
\hline$N$ & 2.814 & 81.90 & 29.1 & 2.885 & 98.90 & 34.3 \\
\hline$\beta$ & 0.0078 & 0.3552 & 45.5 & 0.0064 & 0.3414 & 53.3 \\
\hline$\gamma$ & 0.0003 & 0.3534 & 1178.0 & 0.0002 & 0.3534 & 1767.0 \\
\hline$\mu_{\mathrm{D}}$ & 0.9652 & 0.3787 & 2.5 & 0.97 & 0.3787 & 2.6 \\
\hline$\mu_{\mathrm{To}}$ & 0.911 & 0.0100 & 91.1 & 0.9237 & 0.0100 & 92.4 \\
\hline$\mu_{\operatorname{Tr}}$ & 0.9371 & 0.0027 & 347.1 & 0.9416 & 0.0024 & 392.3 \\
\hline$\phi$ & & Not co & mputed due & aterference & with $N$ & \\
\hline
\end{tabular}

Table 3. Amyloodinium ocellatum. Summary of the mean values $(95 \% \mathrm{CI})$ of the vital rate estimates for $A$. ocellatum infecting spotted seatrout Cynoscion nebulosus and red snapper Lutjanus campechanus. Refer to Fig. 1 for the definition of symbols

\begin{tabular}{|lcc|}
\hline \multirow{2}{*}{$\begin{array}{l}\text { Vital } \\
\text { rate }\end{array}$} & \multicolumn{2}{c}{ Vital rate mean estimates $(95 \% \mathrm{CI})$} \\
\cline { 2 - 3 } & Spotted seatrout & Red snapper \\
\hline$N$ & $81.90(66.10-97.31)$ & $98.90(82.16-115.65)$ \\
$\beta$ & $0.3552(0.3279-3825)$ & $0.3414(0.3122-0.3707)$ \\
$\gamma$ & $0.3534(0.2465-0.4457)$ \\
$\mu_{\mathrm{D}}$ & $0.3787(0.3443-0.4120)$ \\
$\mu_{\mathrm{To}}$ & $0.0100(0.0040-0.0159)$ \\
$\mu_{\operatorname{Tr}}$ & $0.0027(0.0026-0.0029)$ & $0.0024(0.0022-0.0025)$ \\
$\phi$ & $0.39(0.37-0.41)$ & $0.34(0.32-0.36)$ \\
\hline
\end{tabular}

and 92.4 times (for spotted seatrout and red snapper, respectively) to stop an outbreak. Analogously, the mortality rate of the trophont $\left(\mu_{\mathrm{Tr}}\right)$ would need to be increased 347.1 and 392.3 times (for spotted seatrout and red snapper, respectively) to prevent A. ocellatum population growth. The effect of a change in the trophont detachment rate $(\phi)$ was not computed because changes in this vital rate would consequently affect the mean number of dinospores produced per tomont $(N)$.

\section{DISCUSSION}

The Amyloodinium ocellatum matrix population model presented contains all the vital rates that to our understanding modulate the population growth of A. ocellatum and elucidates the relative contribution of each vital rate to the population growth rate $(\lambda)$. This model, along with the accompanying perturbation analysis, may contribute to the development of strategies to prevent or control $A$. ocellatum outbreaks in aquaculture systems.

Like any model, however, the results are dependent on the assumptions built into the model. For example, although the function used to estimate mortality rates could take a variety of forms, an exponential form was chosen based on its reasonable approximation to the data and its simplicity for modeling purposes. Also, apart from the physical characteristics of the environment (i.e. temperature and salinity) that are known to affect the parasite and could be accounted for in our parasite-stage-structured model, other factors external to the parasite and not explicitly considered in the proposed model may affect the parasite's population growth. Among those is fish density, which could facilitate the chances of a dinospore finding a host. Indeed, our own rearing facilities for the size of fish used in these experiments

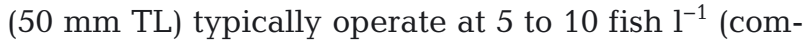
pared to the 0.4 fish $\mathrm{l}^{-1}$ in the experimental exposures). However, we note that in previous experiments (Masson et al. 2011), we found no difference in infection rates in seatrout Cynoscion nebulosus exposed to dinospore doses ranging from 5000 to 200000 dinospores fish $^{-1}$. Stress associated with crowding could make hosts more susceptible to infections (Snieszko 1974, Yin et al. 1995) or perhaps modulate tolerance such that hosts die earlier than expected and produce smaller trophonts that result in fewer dinospores being released. Also, from an (acquired) immunological perspective, previous exposure to the parasite could induce immunity and affect the dynamics of the system. However, Cobb et al. (1998b) found that it takes several exposures to trigger significant immunity. Therefore, the rapid growth of the parasite population would likely produce a lethal level of the parasite before immunity could play a role. Another factor not accounted for in the model was the presence of possible dinosporeeating organisms like brine shrimp nauplii (Oestmann \& Lewis 1995) that would be removing the infectious stages from the system.

Because the number of dinospores produced per tomont $(N)$ had the largest effect on $\lambda$, followed by the dinospore infection rate $(\beta)$, the tomont sporulation rate $(\gamma)$ and the dinospore mortality rate $\left(\mu_{\mathrm{D}}\right)$, controlling these rates should have the greatest effect on parasite population growth. A focus on 
reducing $N$ should result in the greatest reduction in $\lambda_{i}$ therefore, one might, for example, increase the flow of water through the culture system. The detachment of trophonts is dictated by the inability of the rhizoids to maintain attachment to the host. Increased water flow may increase friction and induce trophonts to detach faster (at smaller sizes) than normal and produce fewer dinospores at tomont sporulation (Paperna 1984a). $\beta$ could be reduced through vaccination (Smith et al. 1993, Cobb 1997, Cobb et al. 1998a,b) or selection of less susceptible culture species (Lawler 1977, 1980). Reduced light intensity has been observed to reduce dinospore activity and perhaps infectivity (Brock et al. 1999, Montgomery-Brock et al. 2001). Similarly, $\gamma$ could be minimized by acclimating the cultured fish to temperatures or salinities outside the optimum range for tomont reproduction $\left(18\right.$ to $30^{\circ} \mathrm{C}$ and 10 to $60 \mathrm{ppt}_{\text {; }}$ Paperna 1984a). Finally, $\mu_{\mathrm{D}}$ could be increased by treating the water with chemicals such as copper sulfate which at proper doses would kill dinospores without affecting fish (Dempster 1955, Lawler 1977, Paperna 1984b, Noga \& Levy 2006), by filtering the water to exclude dinospores (e.g. diatomaceous earth filtration) (Bower 1987), or by using nauplii of Artemia salina which have been found to feed on dinospores (Oestmann \& Lewis 1995). Clearly, however, the variables may not be independent. Further research could focus on elucidating how modification of one variable may affect other variables.

A comparison of the vital rate threshold values for Amyloodinium ocellatum population increase (Table 2) with the actual values estimated from the experiments (Table 3 ) shows that increasing $\mu_{\mathrm{D}} 2.5$ and 2.6 times its actual value (in spotted seatrout Cynoscion nebulosus and red snapper Lutjanus campechanus, respectively) would produce a reduction in the parasite's population size. Thus, from a scientific standpoint, this is the vital rate which would need to be the least modified (compared to the 29- to 1178 -fold increases required to affect the other vital rates in spotted seatrout and the 34 - to 1767 -fold increases required for red snapper) to affect the outcome of an outbreak. For the producer, however, the decision as to which treatment to use will be based on cost and effectiveness. Fortunately, copper sulfate at 0.12 to $0.15 \mathrm{ppm}$ for at least $4 \mathrm{wk}$ seems to be a cost-effective method for increasing the dinospore mortality rate and controlling an outbreak (Noga \& Levy 2006).

The trophont detachment probability used in our model corresponds to the age-independent detachment probability. We noted previously that the de- tachment probability varies with trophont age (Masson et al. 2011). However, because our model uses mean values for the considered parameters, we used the trophont-age-independent detachment probability for the analysis. The perturbation analysis suggests that a reduction in $\phi$ should cause a decrease in $\lambda$. However, because the model does not account for the fact that if trophonts remain attached longer they will grow larger and produce more dinospores per tomont (and cause an increase in $\lambda$ ), $\phi$ was not considered in the analysis.

Trophonts tend to remain attached longer and grow larger in red snapper than in spotted seatrout (Masson et al. 2011), and, according to incidental observations, infections seem to reach lethal levels faster in the former host species. Furthermore, the lower $\lambda$ in spotted seatrout $\left(1.90 \mathrm{~d}^{-1}\right)$ compared with red snapper $\left(1.92 \mathrm{~d}^{-1}\right)$, when computed using the actual vital rate estimates obtained from the experiments, also may explain the incidental observations that suggest that, although infections are severe in both hosts, they affect red snapper worse than spotted seatrout. We also reported in a previous study (Masson et al. 2011) that spotted seatrout may withstand a larger trophont load than red snapper. Although we cannot exclude the possibility that spotted seatrout, by virtue of coexisting with Amyloodinium ocellatum in the estuarine environment, have evolved to tolerate more parasites than the red snapper, an offshore species that typically does not encounter A. ocellatum, our proposed hypothesis (Masson et al. 2011) is that red snapper gills may provide a greater surface area (i.e. mean gill area is larger in red snapper than in spotted seatrout, for fish of the same mean weight) on which trophonts can grow larger and inflict more damage at a lower lethal load than those of spotted seatrout. As a consequence, spotted seatrout, by having smaller trophonts, may tolerate more trophonts than red snapper.

Despite the fact that the model presented here only approximates what may be found in culture conditions, the model does provide a framework through which the effects of deviations from these estimated values can be evaluated. Investigation of the effects of deviations from the estimated values and conditions could provide a deeper understanding of the population dynamics of this parasite and lead to improved strategies for control.

Acknowledgements. We thank Drs. Robin Overstreet and Bill Hawkins for their valuable comments on this work. We also are grateful to Verlee Breland, Marie Mullen, James Ballard and Rey de la Calzada for their help in the experimental propagation of A. ocellatum, and to Dr. Ash Bullard 
for providing us with the first infected fish that was used to isolate the parasite. This project was supported by the Mississippi Tidelands Trust Fund Program and the NOAA Science Consortium for Ocean Replenishment (SCORE).

\section{LITERATURE CITED}

Benton TG, Grant A (1999) Elasticity analysis as an important tool in evolutionary and population ecology. Trends Ecol Evol 14:467-471

Bower CE (1987) Update on Amyloodinium. SeaScope 4:1-4

Brock J, Montgomery-Brock D, LeaMaster B, Tamaru C (1999) 1998 annual accomplishment report of the Center for Tropical and Subtropical Aquaculture. Oceanic Institute, Waimanalo, $\mathrm{HI}$

Brown EM (1931) Note on a new species of dinoflagellate from the gills and epidermis of marine fishes. Proc Zool Soc Lond 1:345-346

Brown EM (1934) On Amyloodinium ocellatum Brown, a parasitic dinoflagellate causing epidemic disease in marine fish. Proc Zool Soc Lond 3:583-607

Brown EM, Hovasse R (1946) Amyloodinium ocellatum (Brown), a peridinian parasitic on marine fishes: a complementary study. Proc Zool Soc Lond 116:33-46

Cheung PJ, Nigrelli RF, Ruggieri GD (1978) Scanning electron microscopic observation on the various stages of the life cycle of Oodinium ocellatum (Brown). Trans Am Microsc Soc 98:157 (Abstract)

Cheung PJ, Nigrelli RF, Ruggieri GD (1981) Development of Oodinium ocellatum (Dinoflagellida): a scanning electron microscopy study. Trans Am Microsc Soc 100:415-420

Cobb CS (1997) The immune response of the tomato clown fish Amphiprion frenatus to the parasitic dinoflagellate Amyloodinium ocellatum and selection of candidate antigens for a vaccine. $\mathrm{PhD}$ dissertation, North Carolina State University, Raleigh, NC

Cobb CS, Levy MG, Noga EJ (1998a) Acquired immunity to amyloodiniosis is associated with an antibody response. Dis Aquat Org 34:125-133

Cobb CS, Levy MG, Noga EJ (1998b) Development of immunity by the tomato clown fish Amphiprion frenatus to the dinoflagellate parasite Amyloodinium ocellatum. J Aquat Anim Health 10:259-263

Dempster RP (1955) The use of copper sulfate as a cure for fish diseases caused by parasitic dinoflagellates of the genus Oodinium. Zoologica (NY) 40:133-138

Ebert TA (1999) Plant and animal populations: methods in demography. Academic Press, San Diego, CA

Lawler AR (1977) The parasitic dinoflagellate Amyloodinium ocellatum in marine aquaria. Drum Croaker 17: $17-20$

Lawler AR (1980) Studies on Amyloodinium ocellatum (Dinoflagellata) in Mississippi Sound: natural and experimental hosts. Gulf Res Rep 6:403-413

> Lotz JM, Soto MA (2002) Model of white spot syndrome virus (WSSV) epidemics in Litopenaeus vannamei. Dis Aquat Org 50:199-209

Lotz JM, Flowers AM, Breland VM (2003) A model of Taura

Editorial responsibility: Dieter Steinhagen,

Hannover, Germany syndrome virus (TSV) epidemics in Litopenaeus vannamei. J Invertebr Pathol 83:168-176

McCallum HI (1982) Infection dynamics of Ichthyophthirius multifiliis. Parasitology 85:475-488

> McCallum HI (1985) Population effects of parasite survival of host death: experimental studies of the interaction of Ichthyophthirius multifiliis and its fish host. Parasitology 90:529-547

- Masson I, Blaylock RB, Lotz JM (2011) Susceptibility and tolerance of spotted seatrout, Cynoscion nebulosus, and red snapper, Lutjanus campechanus, to experimental infections with Amyloodinium ocellatum. J Parasitol 97: 577-585

Mathsoft (2005) Mathcad 13. Mathsoft Engineering and Education, Cambridge, MA

Montgomery-Brock D, Brock JA, Tamaru CS (2001) The application of hydrogen peroxide as a treatment for the ectoparasite Amyloodinium ocellatum (Brown, 1931) on the Pacific threadfin, Polydactylus sexfilis. J World Aquacult Soc 32:250-254

Nigrelli RF (1936) The morphology, cytology and life-history of Oodinium ocellatum Brown, a dinoflagellate parasitic of marine fishes. Zoologica (NY) 21:129-164

Noga EJ (1987) Propagation in cell culture of the dinoflagellate Amyloodinium ocellatum, an ectoparasite of marine fishes. Science 236:1302-1304

Noga EJ (2000) Fish disease: diagnosis and treatment. Iowa State University Press, Ames, IA

Noga EJ, Levy MG (2006) Phylum Dinoflagellata. In: Woo PTK (ed) Fish diseases and disorders, Vol 1: protozoan and metazoan infections, 2nd edn. CAB International, Oxford, p 16-45

> Oestmann DJ, Lewis DH (1995) A method for producing microbe-free Amyloodinium ocellatum (Brown) with Percoll $^{\circledR}$. Vet Parasitol 59:169-175

Paperna I (1984a) Reproduction cycle and tolerance to temperature and salinity of Amyloodinium ocellatum (Brown, 1931) (Dinoflagellida). Ann Parasitol Hum Comp 59:7-30

Paperna I (1984b) Chemical control of Amyloodinium ocellatum (Brown, 1931) (Dinoflagellida) infections in vitro tests and treatment trials with infected fishes. Aquaculture 38:1-18

> Smith SA, Noga EJ, Levy MG, Gerig TM (1993) Effect of serum from tilapia Oreochromis aureus immunized with the dinospore Amyloodinium ocellatum on the motility, infectivity and growth of the parasite in cell culture. Dis Aquat Org 15:73-80

Snieszko SF (1974) The effects of environmental stress on outbreaks of infectious diseases of fishes. J Fish Biol 6: 197-208

Systat (2007) Systat, Version 12. Systat Software, Point Richmond, CA

Vincent AG, Breland VM, Lotz JM (2004) Experimental infection of Pacific white shrimp Litopenaeus vannamei with necrotizing hepatopancreatitis (NHP) bacterium by per os exposure. Dis Aquat Org 61:227-233

Yin Z, Lam TJ, Sin YM (1995) The effects of crowding stress on the non-specific immune response in fancy carp (Cyprinus carpio L.). Fish Shellfish Immunol 5:519-529

Submitted: December 27, 2012; Accepted: June 24, 2013 Proofs received from author(s): September 23, 2013 